\section{El cine y esos pueblitos: Mediaciones culturales de la memoria nacional}

Lía Gómez *

Resumen: Roberto Arlt en 1933 publica dos artículos cortos en el Diario el Mundo. "El cine y esos pueblitos" donde cuenta la historia de las jovencitas del interior que ven en las historias fílmicas, la esperanza de ascenso social que retratan en la ciudad de Buenos Aires; y "El cine y sus cesantes" donde propone que aquellas jornadas de cine continuado de las calles La Valle y Florida acobijaban seres sociales que en las pantallas encontraban la posibilidad de imaginar un devenir mejor en plena crisis del '30. ¿Qué sucede hoy con esos mundos, las imágenes y los pueblos? Responder este interrogante necesariamente nos invita a plantearnos, por un lado, la revalorización del papel del Estado en la construcción cultural de un pueblo; y por el otro, la discusión en torno a lo nacional desde las narrativas audiovisuales diversas surgidas en los últimos tiempos.

Palabras clave: Comunicación - Memoria - Identidad - Popular.

[Resúmenes en francés, inglés y portugués en las páginas 139-140]

${ }^{*}$ Dra. en Comunicación. Licenciada en Comunicación Social con orientación en Periodismo por la Facultad de Periodismo y Comunicación Social de la Universidad Nacional de La Plata. Secretaria Académica de la Especialización en Televisión de la FP y CS - UNLP, y Coordinadora académica de la Maestría en Comunicación Digital Audiovisual de la Universidad Nacional de Quilmes. Investigadora categoría III del Sistema de Incentivos. Docente de grado y posgrado. Coordinadora del GT CLACSO en Arte y Política. Directora del Festival de Cine Latinoamericano de La Plata FESAAALP.

\title{
Introducción
}

En la vida se sea o no poeta, se trata de ir reuniendo las cosas de uno.

Hasta las más dispares. Paco Urondo. Junio de 1971. 


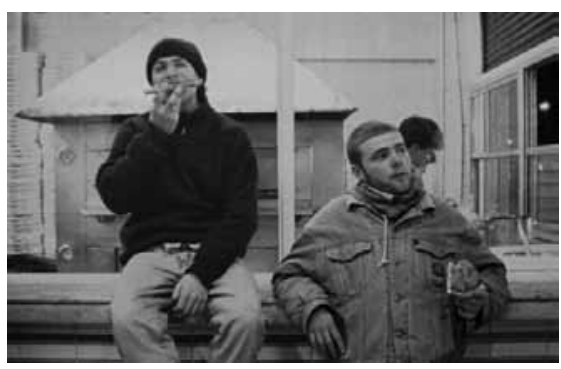

Figura 1. Frame de la película: "Pizza Birra y Faso" (Caetano y Stagnaro 1997-1998).

En noviembre de 1997 aparece en el Festival de Cine Internacional de Mar del Plata, "Pizza, Birra y Faso", film emblemático del cine argentino cuyos directores, Adrián Caetano y Bruno Stagnaro, son parte de lo que en la época se dio en llamar "Nuevo Cine Argentino". En enero del año siguiente (1998) en los cines comerciales se estrenó con gran aceptación en una sociedad golpeada por la crisis de los años '90. Veinte años después, esos jóvenes lúmpenes de la película parecen avizorarse en el universo como espejo de unos años en los que el capitalismo salvaje y la desidia estatal vuelven a ser parte de nuestro cotidiano. Este artículo es redactado en enero de 2018, con un calor sofocante y noticias no mayormente propicias, donde la lucha gremial se ve difamada, el trabajo preocupa día a día, y las valoraciones sobre el futuro de los jóvenes populares de las grandes ciudades se percibe cada vez más obtuso. El cine desde tiempos memorables ha sido un espacio de representación de esos seres sociales que como decía Leonardo Favio incluyen la fe popular como ese motor incansable de amor y de lucha. Pero también, como se ha demostrado en innumerables ocasiones, el pueblo puede ser una caricatura pintoresca costumbrista y poco realista. ¿Cómo se configura entonces una imagen nacional en argentina?, ¿Cómo proyectar una imagen que nos conmueva en lo más profundo de nuestras identidades? Responder estos interrogantes necesariamente no resulta tarea sencilla, ni tenga quizás una sola respuesta posible, pero nos invita a plantearnos, por un lado, la revalorización del papel del Estado en la construcción cultural; y por el otro, la discusión en torno a lo nacional desde las narrativas audiovisuales diversas surgidas en los últimos años.

Roberto Arlt en 1933 publica dos artículos cortos en el Diario el Mundo. "El cine y esos pueblitos" donde cuenta la historia de las jovencitas del interior que ven en los argumentos fílmicos la esperanza de ascenso social que retrataban en la ciudad de Buenos Aires; y "El cine y sus cesantes" donde propone que aquellas jornadas de cine continuado en los cines de las calles La valle y Florida, acobijaban seres sociales que en las pantallas encontraban la posibilidad de imaginar un devenir mejor en plena crisis del ' 30.

El escritor argentino narra con detalle la sensación de desasosiego, angustia y desesperanza de quienes se encuentran deambulando por las calles sin poder tener un pedazo de pan para sus familias, ni un horizonte posible. Escenas que recorren la obra de Arlt entre 
caminos de locura, imaginarios y fabulaciones que permiten a sus personajes mantenerse vivos. Del algún modo, el cine es el motor que moviliza sus conciencias por el tiempo que dura la función continuada, y las vidas de los aconteceres en pantalla remplazan sus cesantes vidas por un momento.

A principios del siglo XX, donde la escritura es aquella que sostiene con mayor narrativa imágenes del cotidiano en los medios masivos como los vespertinos, matutinos y revistas, la pluma de autores incluso no reconocidos en su propio presente, nos posibilitan recuperar no solo las costumbres y quehaceres de la época sino también la trama social, las tensiones e incluso disputas, en este caso por el acceso a la cultura de las clases menos pudientes. En el mismo diario, Arlt intercambia opiniones a través de las cartas de lectores con algún comprador de "El Mundo", que no tolera ver a "holgazanes" en las butacas de la sala a la que asiste, y menos aún encontrar justificado el accionar en aquello que lee.

Treinta años después, pasada la crisis del '30, con la literatura ya establecida, con el auge del cine en los '40, la radio en pleno cauce, y con la reciente aparición de la televisión en el país (1951), Leonardo Favio estrena su primer cortometraje "El amigo" (1960). Narra la historia de dos niños, el primero hijo de un lustrador de zapatos que ayuda a su padre en la puerta del parque de diversiones. El segundo, un jovencito de pantalones cortos y trajes que pasea un carrito de juguetes y de la mano de su progenitor va camino al ingreso a la montaña rusa. Las miradas de ambos se cruzan, y en un fundido a negro, los rostros intercambian los cuerpos que comparten juegos entre risas y gritos de alegría, los autitos chocadores, los botes, la mirada atenta al circo, etc.

Un nuevo fundido trae el primer plano del niño lustrador, que mira al cielo pensativo en su característico banquillo de trabajo. El otro, sale del parque sin su autito y con las lágrimas escurriendo en su rostro, el padre lo lleva a rastras. El pequeño trabajador y su padre toman sus cosas y van camino a casa conversando sobre lo sucedido en la tarde. Ambos ríen, se abrazan.

Es conocida la filmografía del director argentino por su preocupación por las clases populares, los sectores más vulnerables y más auténticos que puede tener una sociedad. Esto se advierte por los prejuicios que corren muchas veces por aquellos que batallan día a día por sobrevivir en un mundo real donde la fantasía también es parte de esa posibilidad. En este breve film, Favio pone claramente en escena ese imaginario con el jovencito que anhela acceder al ocio, al derecho a jugar, a constituir un tiempo para el esparcimiento contraponiendo la mirada solo a la del tiempo útil del trabajo. Tanto en el aguafuerte de Arlt, como en Favio, la diversión es un derecho al que acceder y la cultura un patrimonio de toda la humanidad. Solo en esos encuentros es posible generar por un instante la igualdad.

Volviendo al cine, espectáculo de masas, con exhibiciones públicas y con un ninguneo por parte de las elites más conservadoras en sus inicios, pasa a ser un bien escaso para aquellos jóvenes que hoy no pueden acceder sin que sea una política de Estado. Incluso en los años 2000, en el interior del país, la cinematografía no es parte de los pueblos ni de sus comunidades.

Mejor suerte transita la televisión, que se ha instalado como un elemento en casi todos los hogares siendo objeto de crítica por algunos especialistas que la han denominado "caja boba" o "T.V. basura", y que aún no reconocen el poder de las imágenes en términos positivos y solo pueden verlo desde la negatividad, sin duda existente, de los poderes monopó- 
licos interviniendo sobre las conciencias mediante las imágenes en movimiento. Cuestión a la que no se encuentra ajena el cine en su historicidad.

En la actualidad, el espacio audiovisual se constituye en un lugar de prevalencia de expresiones socioculturales que emergen de la vida cotidiana, y que ponen en disputa la representación de la realidad. Así, los grandes medios masivos de comunicación, consientes del poder de la imagen como constructor de sentido, configuran una imagen de la realidad que muchas veces está disociada de la verdad que se concibe como forma histórica de la sociedad (Gómez y González, 2017, p. 88).

Vivimos una crisis de representación, en épocas donde la "posverdad" se instala como concepto, y las formas de representatividad posibles se ven opacadas por las manipulaciones absurdas de una identidad cultural que por más que se la oculte será develada de múltiples maneras a su tiempo.

\section{Pueblos imaginados, encontrados, representados}

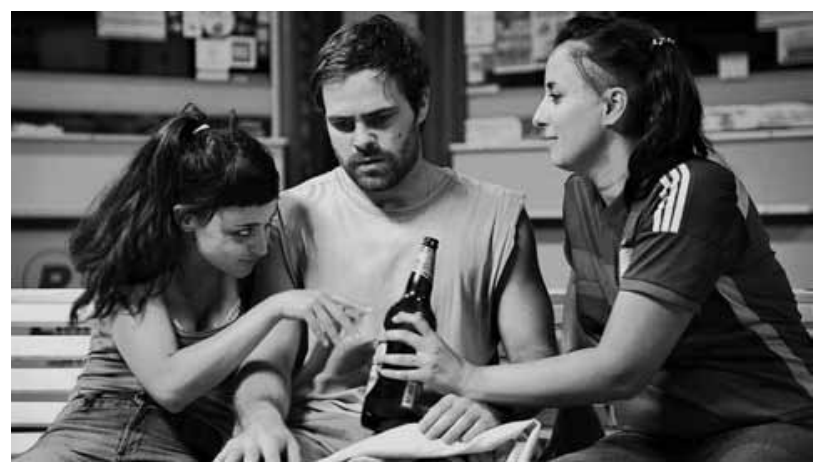

Figura 2. Frame de la serie: "Un Gallo para Esculapio” (Stagnaro 2017).

En toda acción de la cultura que implique imprimir una huella sobre nuestro presente, ya sea literaria, pictórica, fílmica, televisiva, fotográfica, performática, etc., se confecciona el testimonio del presente que aparecerá como testigo de nuestros días en el futuro. Es por ello que pensar cómo se configura la imagen del pueblo en la pantalla resulta, como ya dijimos, un desafío imposible de saldar en un artículo, pero intentamos aquí, seguir la línea del inicio tomando a los cineastas autores Adrián Caetano y Bruno Stagnaro como parte de este recorrido, porque permite ver en sus obras los cambios ocurridos en los imaginarios sobre la Nación en estos 20 años desde el estreno de "Pizza Birra Faso". 
De Adrián Caetano, exponemos unas líneas sobre los Films: "Bolivia" (2001), "Un Oso Rojo" (2002), y "El otro hermano" (2017). “Un gallo para Esculapio” (2017) es la obra de Stagnaro que observamos. Primeramente debemos decir que el concepto de pueblo, tal como indica Marcos Tabarrozzi en su tesis de Maestría en Estética y Teoría de las Artes de la Facultad de Bellas Artes de la Universidad Nacional de La Plata (2016), empieza nuevamente a ser enunciado en los últimos años producto, quizás, de los gobiernos progresistas en América Latina que entienden que la historia debe ser convocada a pensar el presente y que los Estados Nación no están condenados a desaparecer sino más bien, a fortalecerse para generar más condiciones reales de igualdad entre sus ciudadanos.

Así investigadores argentinos como Gonzalo Aguilar (2015), Mariano Metzman (2013), Ana Amado (2013), Carlos Vallina (2015), entre otros, retoman la noción de pueblo para reflexionar sobre la construcción de las imágenes. Claro está que el fenómeno se asocia a las representaciones que este sector brinda para comprender la sociedad en la que surge. Debemos decir que el pueblo siempre fue parte de la preocupación de los artistas comprometidos con su tiempo, ya hemos nombrado aquí a Arlt y Favio; pero por supuesto Rodolfo Walsh, Paco Urondo, Manuel Puig, Leopoldo Torre Nilsson, Pino Solanas, Octavio Getino, y podríamos seguir nombrando.

Difícilmente haya un solo modo de concebir un concepto tan complejo como "el pueblo", sin embargo podemos acordar -provisoriamente- que se constituye como identidad interclasista, pero al mismo tiempo como "contra-hegemónico, con base en un proletario, como concepto asociado al trabajo" (Tabarozzi, 2016, p. 10). Aquí entonces trabajo y pueblo parecen estar asociados. Alcira Argumedo plantea que:

El concepto de pueblo entonces hace referencia a la construcción de un bloque político-social del conjunto de las clases subordinadas, cuyas características son esencialmente históricas, ya que la composición en clases y fracciones sociales que han ido integrando esos movimientos populares ha adquirido rastros disímiles en los distintos países y coyunturas de la historia (2011, p. 210).

Desde el campo de la imagen, Didi-Huberman (2014), propone pensar en unos pueblos expuestos que no sean figurantes de la imagen, sino que se expongan en su verosimilitud como parte de un reflejo de lo real permitiendo observar más allá de la superficie que los cuerpos emanan en su forma estructural. Es por ello, que las representaciones de lo popular se tornan tan históricamente situadas y, en paralelo, temporalmente verosímiles, en tanto y en cuento, la estructura de la representación debe ser concebida como un elemento de configuración de una verdad de ese pueblo como ser nacional. Un ser que se conforma en la historia política social y cultural y que conlleva en los surcos que la interpretación expone, las propias condiciones de opresión y de lucha que lo popular encuentra para emerger como visibilidad.

Pero: ¿Cuáles son esas condiciones en las representaciones audiovisuales argentinas? Sin duda la familia, el trabajo, el progreso y el futuro. El pueblo invisibilizado por el poder hegemónico es lo que el cine debería visibilizar en sus intersticios, detalles, vestigios y conflictos de una amalgama para nada homogénea. 
El film "Bolivia" (2001) inicia con una de las imágenes más simples, más vistas y más bellas expuestas en la historia cinematográfica en Argentina, un partido de fútbol entre Argentina y Bolivia en blanco y negro, con algunas interferencias y una música de fondo típica del país vecino que nos anuncia la comunidad inevitable de ambas comunidades. Acto seguido, Freddy, un boliviano recién llegado a Buenos Aires encuentra trabajo en una parrilla y empieza una vida de cruce con actores sociales de la Capital porteña fuera del paisaje turístico, taxistas, borrachos de bares opacos, emprendedores clandestinos, vendedores ambulantes, el mismo dueño de la parrilla y una camarera paraguaya.

El blanco y negro, asociado a los planos cercanos de cada objeto que comparte escena con los personajes, hace de la atmósfera del lugar un espacio habitable para el espectador que encuentra en el film, la sensación de sofocamiento de una sociedad que si no se reconoce a sí misma está condenada al fracaso. Pero hay algo a lo que Freddy no renuncia, la comunicación con su familia, el sueño del progreso, de un futuro con su trabajo, y el amor como única posibilidad de la esperanza.

"Un oso Rojo" (2002) repite el esquema, pero con forma de western del oeste del conurbano bonaerense. El personaje interpretado por Julio Chavez tiene la tragedia en su destino como parte indisociable de su sacrifico por la pequeña hija, y la imposibilidad de un futuro diferente. Donde la desidia se metaforiza en la escena del acto escolar con el himno de fondo, los pequeños de guardapolvos blanco entonando entre paredes despintadas, los padres observando abúlicos, y en contra-plano el Oso en un tiroteo con semejantes, pero policías en el robo de un banco.

En estas producciones de principios de los 2000, así como en el film del '98, el Estado solo aparece como fuerza de represión y corrupción, y nunca como garante de derecho al trabajo, y menos aún al ocio, al espectáculo, salvo para ver allí la propia tragedia, como la niña de "Un oso rojo" al que la madre le lee un cuento de Horacio Quiroga: "Las medias de los flamencos" (1918).

Caetano sigue en su filmografía y sorprende con "Francia" (2013) donde enfoca la mirada en una familia de clase media venida a menos que tiene problemas con su pequeña hija en una escuela privada. Revaloriza el papel del Estado, y a diferencia del film anterior, es la escuela pública el lugar de referencia de la condición de igualdad y felicidad. No nos detendremos aquí en este film, pero lo exponemos como clave para pensar la historicidad de la obra de Caetano en estos años.

En 2017, se estrena "El otro Hermano". Daniel Hendler ocupa el papel protagónico e interpreta a un joven empleado público que recibe una herencia en un pueblito del Chaco. El actor, conocido por su participación en la publicidad de Telefónica a principios de los 2000, mantiene su caracterización de personaje abúlico, opaco, tal como incluso personifica en el film uruguayo " 25 watt" -Rebela y Stoll-, o en los primeros del director Daniel Burman "Esperando al mesías" (2000), y "El abrazo partido" (2003). Tal caracterización, acompañada por la cámara que lo sigue casi enfocando su desconcierto y desinterés frente al mundo, configura también en el film de Caetano el ritmo de la película.

El personaje de Hendler abomina su empleo en una oficina en Buenos aires donde no tiene capacidad de proyección y solo puede ser salvado por la herencia que logra cobrar de modo estrafalario, con la ayuda de un policía del lugar -Leonardo Sbaraglia-, un personaje sombrío, oscuro que parece haber incluso participado de la tortura en la época de la 
dictadura cívico militar. A la manera de "Pizza, Birra, Faso", el Estado ausente que dispone el destino trágico de sus personajes, aparece en su peor faceta como escenario de abandono, tortura, especulación y corrupción. La cámara inicia su recorrido en una parada de micro herrumbrada por el tiempo y una calle de tierra con la luz sobre el polvo de un calor sofocante. Todas las escenas irradian en pantalla el clima soporoso del Chaco, con espacios desteñidos, hierros oxidados, chatarra vieja, maderas podridas y carteles puestos como promesa de construcciones olvidadas ocupan todo el paisaje. Los que allí habitan intentan sacar ventaja de lo poco que tienen. En el film, la especulación es la acción principal. El actor Pablo Cedrón, interpreta a un cojo charratero que vive con su hijo de comprar y vender tratos viejos para acumularlos en un galpón sin mayor proyecto que ese, y finalmente Hendler termina sus días manchado en sangre huyendo rumbo a Brasil.

Pareciera ser que el interior del país, es ese lugar detenido en el tiempo donde solo es posible la indiferencia, donde no hay lugar para el amor, ni la alegría, ni la compasión siquiera por el otro semejante. ¿Es este el pueblo que configura las provincias donde aún no ha llegado la modernidad, tal como la describieron los autores europeos? ¿Dónde se encuentra entonces la riqueza de una América Latina que en la tradición de su cultura enriquece a los personajes de pueblos olvidados, tal como nos ha enseñado el propio Juan Rulfo o Gabriel García Márquez? ¿Qué ha sucedido en estas representaciones con el contexto de gobiernos que han apostado a la valorización de sus pueblos en el continente americano?

En Zama -Lucrecia Martel- también de 2017, el protagonista principal, Don Diego de Zama espera hasta el final su traslado a España. Vive en similar situación de sopor y hartazgo sus días en un pueblito de frontera en las costas del Paraguay. No logra encontrarse con los habitantes que esas tierras deambulan, ni conectarse con la historia más allá de la ambición de salirse de ese espacio. El tiempo detenido también parece ser el personaje principal. Contrario a los films anteriores de la directora salteña, donde la vida transcurre con las complejidades que el mundo mismo depara, pero con la certeza del reconocimiento como principal valor para vivir en sociedad.

En la propia novela (1956) del escritor mendocino Antonio Di Benedetto, Zama espera pero no huye de lo real, encuentra allí el amor, la esperanza, un hijo que ha dejado, y el paisaje aparece con la belleza propia de la naturaleza, de un espacio que está en plena lucha de dominación y supervivencia. Las tensiones del progreso, las decisiones políticas del hombre han moldeado la cultura, y la novela lo expone con una narrativa exorbitante. Sin embargo, el film de Martel no logra escapar de la opacidad de una mirada que solo puede explicarse en estos tiempos donde la desconfianza en la política pareciera ser el motor social.

Reflexionar sobre las políticas de la representación implica, no solo pensar en el accionar de lo público como intervención para la producción de narrativas de nuestra identidad, sino también, comprender como se configuran imágenes políticas de un pueblo, cuyas temporalidades e historia, han sido marcadas por los devenires de cruces culturales a lo largo de los siglos de la denominada civilización. Entonces, abogar por una política de la representación de los pueblos conlleva también a sostener la responsabilidad de la construcción de una imagen pública que contenga e integre esas complejidades.

Poco tiempo después del film de Martel, ha salido publicado un pequeño texto de una autora entrerriana, Selva Almada, que presenció el rodaje de la película y transformó sus anotaciones en breves notas o relatos de ese viaje. 
La mayoría de los actores vive en el barrio Nam Qom, uno de los más populosos y pobres de la ciudad de Formosa. Las casas de material conviven con chozas hechas de nylon, cartón, chapa (...). En casillas así viven dos muchachos veinteañeros, cuñados entre sí, padres de hijos pequeños que vinieron del campo hace dos años. No tienen trabajo. En la película son dos guerreros fuertes y hermosos (...). Alguien del equipo técnico habla con ellos mientras esperan para rodar sus escenas. ¡Pero ustedes no cultivan, no crían gallinas! Ahí nomás en un pedacito de tierra que tengas, podés hacer un montón de cosas, y por lo menos van a comer todos los días ¿o no? Los muchachos se miran, sonríen y no le contestan. Los Qom son pescadores y recolectores. No saben plantar (Almada, 2017, pp. 27, 28).

En el breve escrito, se devela mucho más de lo que el film de Martel logra hacer visible. Ese pueblo de Chaco, donde ha ido a filmar la tierra lejana de don Diego de Zama, en realidad es más similar al mundo de la novela de lo que la representación permite acceder. Allí, la confianza en los artificios de la imagen opaca lo real y lo desarticula en su verdad más políticamente pura. De modo tal, que el escrito de Almada resulta mayormente real maravilloso como diría Carpentier (1949), que el propio universo que Martel intenta imprimir en pantalla, y así la trama y densidad de la novela se ve mayormente reflejada como parte de un cotidiano que aún hoy sigue existiendo. Esos muchachos, como don Diego, siguen en el tiempo de la espera, con la esperanza de un reconocimiento, un conocimiento del otro que los legitime y enaltezca en su condición de ciudadanos.

Bruno Stagnaro estuvo ausente como director varios años, volviendo finalmente a la pantalla -esta vez televisiva-, con un "Un gallo para Esculapio", producción estrenada en 2017. La serie que ha concebido hasta ahora una sola temporada, sea quizás una de las narrativas de estos últimos años que mejor ha caracterizado lo popular en las representaciones audiovisuales.

Nelson -Peter Lanzani- es un muchacho misionero que llega a Buenos Aires en busca de su hermano Roque-Diego Cremonesi-. Solo trae consigo un gallo de riña que será quien lo acompañe hasta conocer al Chelo Esculapio -Luis Brandoni-. La trama circula entre las peleas clandestinas, las horas en un lavadero de autos fantasma y el gran negocio del robo de camiones con cargas millonarias en las rutas del conurbano bonaerense. La cámara acompaña cada movimiento tomando los detalles de un territorio tan hostil como apasionado, como la venta en los comercios de Liniers en medio de una procesión por los tiempos de festejo del carnaval boliviano, las pensiones de mala muerte, y el comercio paralelo de los nigerianos. Los personajes deambulan en busca de un amor que no han encontrado, desde los más secundarios como la esposa del Chelo, o los compañeros de vivienda de Nelson; así como la muchacha que se interpondrá entre dos hermanos, en realidad tío y sobrino donde las relaciones de poder se visibilizan al final de la serie, como la muchacha que atiende el lavadero de autos y que sobrevive en un mundo altamente machista.

La familia adquiere aquí principal protagonismo, no por su condición de sangre sino de sus experiencias de vida, donde los valores y los lazos sociales son re-significados en virtud de la supervivencia en la jungla de cemento, como recurrentemente se ha dado en llamar al gran Buenos Aires. Lo interesante de la apuesta, es que Stagnaro no abandona nunca 
su fe en esos seres sociales, a los que no condena en momento alguno, sino que más bien intenta comprenderlos en la complejidad de sus temporalidades subjetivas. Así mismo, la mirada sobre un territorio mediáticamente estigmatizado, adquiere una condición de belleza inigualable, porque el lente observa la humanidad detrás de cada gesto, cada acto y cada huella dejada por la cultura suburbana en este tiempo y pedacito de tierra que alberga a millones de seres de múltiples partes. La multiculturalidad de los personajes que habitan la serie, lejos de caer en el costumbrismo, imprimen en pantalla sonoridades y tonalidades diferentes que confeccionan la riqueza y a su vez la dificultosa definición de las características de ese pueblo representado en todas sus facetas.

En "El Romance del Aniceto y la Francisca, de cómo quedó trunco y algunas cosas más" (1967) así como en el "Aniceto" (2008) de Leonardo Favio, el gallo es uno de los elementos centrales de las desventuras del personaje interpretado en su primer versión por Federico Lupi, y en la más reciente por Hernán Piquin. El gallo de riña es la fortuna que pierde por amor el personaje, recuperarlo lo llevará a la tragedia de su muerte contra un paredón, es la condena por la imposibilidad de amar de los personajes, por la ceguera de la codicia, o quizás por el inoportuno pasar que no observa el futuro como horizonte posible. El gallo que protagoniza el cuento "El Cenizo de Zuhair Juri" que es llevado al cine por su hermano, en la seria de Stagnaro también se torna central. Es el que une los personajes, los separa y mantiene el punto de tensión hasta el final. Es aquel que pelea por su propia vida, como Nelson, como Chelo, y como todos los involucrados en esta trama temporal. Sin pelea no hay vida en un mundo donde las condiciones sociales son la lucha o la muerte. Pero aún en las condiciones más atroces para que haya humanidad la dignidad, la esperanza y el amor siempre serán parte de esas relaciones, de esas representaciones.

\section{Algunas líneas para terminar/empezar}

A lo largo del escrito hemos empezado a preguntarnos por las representaciones del pueblo, en algunas producciones nacionales contemporáneas. La literatura, el cine y la televisión forman parte de los lenguajes que abordamos como una amalgama en permanente diálogo, que compartiendo el tiempo, propone reflexionar desde la ficción sobre la cultura que nos atraviesa en el campo de lo real y cotidiano.

En tiempos donde la posverdad pareciera explicarlo todo, debemos sin embargo mantener alerta el pensamiento para comprender que las narrativas y representaciones también son parte de la responsabilidad de una época, y que si no reconocemos los propios modos de contarnos, lejos estaremos de conseguir la libertad estética y menos aún política para un accionar libre e igual de los ciudadanos. Se trata quizás, de comprender el mundo en su esteticidad histórica, en sus múltiples formas de narrarse en función de las condiciones sociales, y no por sobre y para esas condiciones. Se trata, para decirlo de otro modo, de comprender el lenguaje de la época y saber enunciarlo; solo así podremos configurar una imagen del pueblo que somos, asumiendo la condición de igualdad frente a la heterogeneidad. No podemos decir que hemos acercado una respuesta a los interrogantes planteados, pero sí que iniciamos un camino donde preguntarnos por las imágenes de los pueblos en Argentina para poner en tensión el lugar de la construcción social de sentido, que en las 
primeras teorías de la comunicación se ubicaba en los medios, luego en las mediaciones, y que quizás debiera estar en el intersticio entre ambas, en esa articulación donde la cultura conforma los debates entre lo masivo y lo popular en la comunicación. Desde allí, las identidades se van forjando no como producto de la posverdad, y de la manipulación, sino más bien, de la verdad posible para los que viven en condiciones de opresión constante.

En "Pizza birra y Faso", el personaje de Sandra huye a Uruguay al final del film con un hijo por venir como esperanza de futuro. Veinte años después, el que interpreta Daniel Hendler solo lleva su soledad y dinero, pero Nelson, espera a la vera de la ruta con un pequeño mapa hecho en papel blanco de cómo moverse en el oeste del conurbano, una promesa hecha al Chelo y un amor y lealtad profunda a los seres que lo acompañan.

Las mediaciones culturales sobre la identidad, sobre el presente y su contexto aparece en estas obras en constante tensión, quizás siendo el único modo de configuración de la memoria del propio tiempo, de un devenir inestable, que a años de la Conquista sigue hablando de negros y blancos, de patrones y empleados, de luchas desiguales de género, de no reconocimiento a la diversidad, e incluso, de no reconocimiento de derechos como el trabajo, la previsión, la educación y la soberanía no solo política sino también económica y cultural. Al fin y al cabo, la representación de un pueblo, en todos sus órdenes posibles, es la piedra fundamental para el desarrollo de la democracia. Así, lo entendían los griegos y quizás por eso, "Un gallo para Esculapio" sea más aún que solo una metáfora en mención a la frase final de Sócrates al ser condenado, quizás sea la necesidad de saldar la deuda con una imagen propia que permita conservar al ser nacional en toda su plenitud y complejidad.

\section{Referencias Bibliográficas}

Aguilar, G. (2015). Más allá del pueblo. Imágenes, indicios y políticas del cine. Buenos Aires, Argentina. Ed. Fondo de Cultura Económica.

Almada, S. (2017). El mono en el remolino. Notas del rodaje de Zama de Lucrecia Martel. Buenos Aires, Argentina. Ed. Random House.

Argumedo, A citado en, Tabarozzi, M. (2016). Crisis de la conciencia. La aparición del pueblo en cuatro filmes del cine moderno argentino (1959-1988). Tesis de Maestría en Estética y Teoría de las Artes. FBA UNLP. Recuperado de: SEDICI - UNLP.

Didi-Huberman, G. (2014). Pueblos expuestos, pueblos figurantes. Buenos Aires, Argentina. Ed. Manantial.

Di Benedetto, A. (2017). Zama. Buenos Aires, Argentina. Ed. Adriana Hidalgo.

Fontana, P. (2009). Arlt va al cine. Buenos Aires, Argentina. Ed. Libraria.

González, D. y Nicolosi, P. (2017). “La televisión Universitaria”. En: Transiciones de la escena audiovisual. Perspectivas y disputas. Quilmes, Argentina. Ed. UNQ. 2017.

Metzman, M. y Varela, M. (2014). Masas, pueblo, multitud en cine y televisión. Buenos Aires, Argentina. Ed. Eudeba.

Tabarozzi, M. (2016). Crisis de la conciencia. La aparición del pueblo en cuatro filmes del cine moderno argentino (1959-1988). Tesis de Maestría en Estética y Teoría de las Artes. FBA UNLP. Recuperado de: SEDICI - UNLP. 
Vallina, C. (2016). El tercer relato. La Plata, Argentina. Ed. Edulp.

\section{Filmografía videografía}

Caetano, A. y Stagnaro, B. (1998). Pizza Birra Faso. Argentina.

Caetano, A. (2001). Bolivia. Argentina.

Caetano, A. (2002). Un oso Rojo. ArgentIna.

Caetano, A. (2017). El otro hermano. Argentina.

Stagnaro, B. (2017). Un Gallo para Esculapio. Argentina.

Favio, L. (2008). Aniceto. Argentina.

Favio, L. (1960). El amigo. Argentina.

Favio, L. (1967). El romance del Aniceto y la Francisca de cómo quedó trunco y algunas cosas más. Argentina.

Martel, L. (2017). Zama. Argentina.

Rebella, P. y Stoll, P. (2001) 25 watt. Uruguay.

Résumé : Roberto Arlt en 1933 publie deux courts articles dans le journal El Mundo : "Le cinéma et ces petites villes", qui raconte l'histoire de jeunes provinciales qui voient dans les histoires des films l'espoir d'ascension sociale dont elles dressent le portrait dans la ville de Buenos Aires; et "Le cinéma et ses désœuvrés" où il propose que ces journées de cinéma se poursuivent dans les cinémas des rues La Valle et Florida, abritant des individus qui trouvent sur les écrans de quoi imaginer un avenir meilleur en pleine crise des années 1930. Que se passe-t-il aujourd'hui avec ces mondes, ces images et ces populations ? Répondre à cette question invite nécessairement, d'une part, à réévaluer le rôle de l'État dans le développement culturel de la population, et d'autre part, à aborder les débats sur l'identité culturelle dans les divers récits audiovisuels apparus ces derniers temps.

Mots-clés : Communication - Mémoire - Identité - Populaire.

Abstract: Roberto Arlt in 1933 publishes two short articles in the newspaper El Mundo. "The cinema and those small towns" where it tells the story of young girls from the interior who see in the film stories the hope of social uplift that they portray in the city of Buenos Aires; and "The cinema and its unemployed" where it proposes that those days of cinema continued in the cinemas of the streets La Valle and Florida, shelter social beings that on the screens find the possibility of imagining a better future in the midst of the 30's crisis. What's happend today with those worlds, images and peoples? Answering this question necessarily insvites us to consider, on the one hand, the revaluation of the role of the State in the cultural construction of a people; and on the other, the discussion about the national from the diverse audiovisual narratives that have arisen in recent times.

Keywords: Communication - Memory - Identity - Popular. 
Resumo: Roberto Arlt em 1933 publica dois curtos artigos no jornal El Mundo. "O cinema e as pequenas cidades", onde conta a história de jovens do interior que vêem nos filme a esperança de elevação social na cidade de Buenos Aires; e "O cinema e os desempregados", onde propõe que esses dias de cinema de La Valle e da Flórida, abrigam seres sociais que, nas telas, encontram a possibilidade de imaginar um futuro melhor em meio à crise dos anos '30. ¿Que acontece hoje com esses mundos, imagens e povos? Responder a esta pergunta necessariamente nos convida a considerar, por um lado, a revalorização do papel do Estado na construção cultural de um povo; e, por outro lado, a discussão sobre o nacional das diversas narrativas audiovisuais que surgiram nos últimos tempos. Entendemos o campo específico como espaço político, social e cultural; para o qual o público dá sentido à expressão de cada história que a mídia propõe.

Palavras chave: Comunicação - Memória - Identidade - Popular.

[Las traducciones de los abstracts al francés, inglés y portugués fueron supervisadas por el autor de cada artículo] 